\title{
A ironia ovidiana na subversão do protocolo amoroso em Roma
}

Ovidian Irony in the Subversion of the Rome Protocol of Love

L'ironie ovidienne dans la subversion du protocole amoureux à Rome

\section{Carlos Ascenso André}

\section{OpenEdition}

\section{Journals}

Edição electrónica

URL: http://journals.openedition.org/rccs/3672

DOI: $10.4000 /$ rccs.3672

ISSN: $2182-7435$

\section{Editora}

Centro de Estudos Sociais da Universidade de Coimbra

\section{Edição impressa}

Data de publição: 1 Junho 2010

Paginação: 41-54

ISSN: 0254-1106

\section{Refêrencia eletrónica}

Carlos Ascenso André, « A ironia ovidiana na subversão do protocolo amoroso em Roma », Revista Crítica de Ciências Sociais [Online], 89 | 2010, colocado online no dia 01 outubro 2012, criado a 02 maio 2019. URL : http://journals.openedition.org/rccs/3672 ; DOI : 10.4000/rccs.3672 


\title{
CARLOS ASCENSO ANDRÉ
}

\section{A ironia ovidiana na subversão do protocolo amoroso em Roma}

\begin{abstract}
Uma leitura menos atenta da Arte de amar, de Ovídio, parece sugerir que o poeta enquadra este seu manual da ciência amorosa nos códigos sociais do seu tempo, que secundarizavam a mulher e dela faziam apenas objecto do desejo e prazer do homem e uma espécie de aparelho reprodutor. Uma leitura mais atenta deixa perceber conclusões bem diferentes: é reconhecido à mulher o direito ao prazer, a escolher (ou rejeitar) o seu parceiro, a trair; é até defendido o prazer mútuo e simultâneo como um dos objectivos do acto sexual. O presente trabalho pretende demonstrar esta subversão ao "protocolo amoroso" de Roma, visível nos Amores, e comprovada nas Heroides, o primeiro livro de poemas de autor masculino mas de sujeito poético feminino, e ainda nos Remédios para o amor, livro de uma fina ironia, onde se esconde o reconhecimento do primordial papel da mulher na relação entre os sexos.
\end{abstract}

Palavras-chave: amor; ironia; literatura; mulheres; Ovídio; relações homem-mulher; Roma Antiga; sexo.

Instrumento ao serviço do prazer masculino; um ser sem identidade, quase sem nome; objecto de contrato, nos esponsais, e nunca parte contratante; eis algumas das características da mulher na sociedade romana, três exemplos, apenas, de entre as inúmeras situações que poderiam ser referidas.

No casamento, os pais negociavam-na, sem que, no acordo, ela pudesse ter parte activa ou vontade. A própria linguagem o deixa claro: aquilo que, hoje, traduzimos com o verbo "casar" expressava-se, em latim, de forma diversa, consoante fosse o homem ou a mulher o sujeito da frase. Se fosse homem, dizia-se ducere, forma abreviada de ducere uxorem ou ducere in matrimonium (à letra, "conduzir como esposa" ou "conduzir ao casamento"); se fosse a mulher, ou a frase se dizia na voz passiva, duci ("ser conduzida"), ou com um outro verbo, intransitivo, ou seja, sem complemento directo, nubere. Em suma, a gramática não consentia à mulher ser sujeito de verbo transitivo de que fosse o homem o complemento directo. Um ser sem identidade, também, já que, ao contrário dos homens, que tinham três 
nomes (Octávio César Augusto, Marco Túlio Cícero), as mulheres apenas tinham um, o do pai: Lívia seria a filha de Lívio, Lúcia a de Lúcio e assim por diante. E, finalmente, no sexo, um instrumento ao serviço do prazer do homem, a quem devia servir, nomeadamente como uma espécie de aparelho reprodutor, para dar continuidade à família.

Tudo isso o exprime, em verso, Catulo, um poeta da primeira metade do século I a. C. As palavras são elucidativas:

A virgindade não é, toda ela, tua, vem já da parte dos pais;

uma terça parte foi dada ao teu pai, uma outra terça parte à tua mãe;

só a terça parte te pertence; não queiras contender com eles dois,

que ao genro cederam os seus direitos juntamente com o dote.

(Catulo, 62.62-65) ${ }^{1}$

Num outro passo do mesmo poema esta relação é confirmada: "Os acordos que firmaram os maridos, já antes os firmaram os pais” (Catulo, 62.28). A respeito do prazer e do casamento, ordena à mulher que sirva o marido, para que, com a sua recusa, não legitime a infidelidade dele:

E tu, também, agora esposa, quanto o teu

marido te pedir, livra-te de o negares,

para que não vá alhures satisfazer o pedido.

(Catulo, 61.151-153)

Houve algumas mulheres, é certo, na história de Roma, que se destacaram pela afirmação da sua personalidade ou por terem desempenhado um papel activo em determinada conjuntura da sociedade romana; nelas se confunde, não raro, a lenda com a verdade histórica, o que não deixa de ser sintomático. São, porém, excepções que mais não fazem do que confirmar a regra, ${ }^{2}$ além de que é duvidoso que tal protagonismo tenha a ver com qualquer forma de reconhecimento do seu direito a uma identidade própria.

Ovídio, poeta latino nascido no mesmo século que viu florescer Catulo, mas já na segunda metade, na antevéspera do Império, é um homem do seu tempo: nele forjou a sua personalidade, nele se construiu e afirmou,

\footnotetext{
${ }_{1}$ Todas as traduções de textos latinos são de minha responsabilidade.

${ }^{2}$ Entre os diversos estudos disponíveis a este respeito, ver, por exemplo: Fantham (1994), Gourevitch et Raepsaet-Charlier (2001).
} 
como homem e como poeta. Poeta de corte, além do mais, uma espécie de trovador de salão, requestado para festins e banquetes, naquela Roma que começava a ver germinar os frutos do luxo importado do Oriente. Cantor da moda, dir-se-ia, a esse ambiente adequava os seus versos, para justificar a popularidade com que lhos pagavam.

Nenhuma surpresa, por isso, constitui o começo do seu manual da ciência amorosa, a Arte de amar, onde, ao longo de três livros e mais de dois mil e quinhentos versos, inicia os seus contemporâneos (e as suas contemporâneas) nas lides do amor, no qual se dizia versado e que assumia poder ser aprendido e cultivado, como qualquer outra técnica. Aí, o homem é, desde o início, apresentado como um predador, em contraponto ao retrato da mulher, configurada como presa. Para definir os lugares onde se dedicar à sedução, recomenda ele aos homens que façam como o caçador, que sabe bem em que lugares vagueiam veados e javalis; como o passarinheiro, que conhece os arbustos a que se acolhem os pardais; ou como o pescador, que busca, certeiro, as águas onde nadam os maiores cardumes. ${ }^{3}$

Ao homem cabe, assim se diz logo nos primeiros versos, a iniciativa; mal vai aquele que deixa à mulher tomar a dianteira no processo de sedução. E tem, mesmo, direito à violência, se acaso a mulher que lhe alimenta o desejo rejeita as suas arremetidas. Com a violência a dobrará. Disso deram exemplo, recorda, os guerreiros de Rómulo, quando raptaram as jovens sabinas - elas acabaram por entregar-se-lhes, depois de arrebatadas à família.

Mas, se assim é um tal poeta, cuja frontalidade, se a este passo se restringisse, nos choca, como se compreende que, em 1985, um painel da prestigiada American Philological Association lhe fosse inteiramente dedicado, todo ele composto por assumidas feministas, estudiosas dos Clássicos, com o objectivo de, como diziam, "recentrar" o seu texto? E como se compreende que algumas delas o tenham, mesmo, apontado como uma espécie de pioneiro, em Roma, de ideologias que só o futuro veria desabrochar, assentes na afirmação do estatuto da mulher? Tratou-se de um painel controverso, esse, a julgar pela polémica que desencadeou; mas há que reconhecer serem fundadas muitas das suas afirmações. ${ }^{4}$

Ensaiemos uma explicação, porventura simplista, mas verosímil, para este aparente paradoxo ovidiano: poeta do seu tempo e, além do mais, de salão, cantor popular, Ovídio quis deixar, na abertura da sua Arte, um pórtico que não arredasse os seus leitores, acostumados a ver a mulher como a

\footnotetext{
${ }_{3}$ Ver, a este respeito, Green (1996).

${ }^{4}$ Várias dessas intervenções estão reproduzidas em Helios 17.2 (1990); vide dois exemplos na bibliografia final.
} 
celebrava Catulo. Se de outra forma agisse, vale a pena perguntar, será que a sua popularidade seria a mesma? Por outro lado, a verdade é que a leitura atenta dos seus versos permite descortinar, neste comportamento masculino, muitas brechas e inúmeras contradições. O que pode levar a intuir (e mais do que intuir talvez não seja possível) que a abertura da Arte de amar, bem como muitos outros dos seus passos, assentam numa profunda ironia.

Senão, vejamos: é Ovídio o poeta do amor, por excelência. $\mathrm{O}$ maior poeta de amor de Roma, o que não é pouco, se tivermos em conta que o século I a. C. produziu muitos poetas que a esse tema dedicaram grande parte da sua obra: Catulo, Propércio, Tibulo, Galo serão os exemplos mais significativos. Ora, para um poeta de amor, inserido no seu tempo e a ele afeiçoado, esse tempo masculino, se assim pode dizer-se, não deixam de suscitar perplexidade e admiração alguns aspectos da sua obra.

Publicou, por exemplo, uma colectânea de poemas, as Heroides, quase todos numa voz feminina. São vinte e uma cartas, dezoito das quais dirigidas por mulheres míticas aos seus amados (os quais, em boa parte dos casos, as haviam abandonado). Trata-se de algo inédito em Roma, a menos que se aceite a teoria, mais do que discutível, de que a poeta Sulpícia fosse um pseudónimo de Tibulo. No entanto, mesmo se assim fosse - e trata-se apenas de uma diferença entre outras - seria de realçar que Tibulo estaria a esconder a sua autoria por detrás de um nome de mulher, ao passo que Ovídio se assume como autor dos poemas, a que dá um sujeito enunciador feminino.

Escreveu ainda um livrinho, que tem por título Remedia amoris (Remédios para o amor), ${ }^{5}$ onde ensina os homens a resistirem aos malefícios das mulheres ou a deles se curarem. É, em boa verdade, um divertido prodígio de ironia, de onde ressalta, a todo o tempo, a ideia de que, no amor, o protagonismo compete à mulher e o homem não passa de uma sua vítima, a quem é preciso tudo ensinar, para se não vergar às artes mágicas de tão poderosa adversária.

Acresce que celebrou, pelo menos em dois poemas, o aborto; ${ }^{6}$ ainda que o faça para o condenar, este não era seguramente um tema que caísse bem no conservadorismo típico da política de Augusto. Por outro lado, desdobra-se em conselhos à mulher sobre como praticar a infidelidade. E ainda, dos três livros da Arte de amar, um deles é dirigido às mulheres, a quem reconhece o direito de aprenderem os mesmos preceitos que nos dois livros anteriores ensinara aos homens. No seu conjunto, todos estes aspectos reflectem

\footnotetext{
5 Não existe tradução portuguesa.

${ }^{6}$ Amores, 2.13 e 2.14 .
} 
um percurso aparentemente trilhado ao arrepio da moral vigente e pouco consentâneo, repita-se, com os princípios conservadores que caracterizavam a política do Imperador, nomeadamente no que respeita às relações entre sexos.

Isto não significa, importa, desde já, deixá-lo claro, que Ovídio seja, neste aspecto, uma espécie de visionário, nem que seja um defensor, por antecipação, dos direitos da mulher, numa sociedade marcada pelo primado do masculino, nem um porta-estandarte, com dois mil anos de antecedência, de teorias feministas. Não podem, em todo o caso, deixar de surpreender-nos, pelo contexto em que foram produzidas, algumas afirmações dos seus poemas e muitas das suas atitudes, poeticamente assumidas. Olhemos algumas delas em pormenor.

Desde logo, o implícito (e, por vezes, explícito) reconhecimento do direito da mulher a uma opção afectiva e, não raro, sexual, já que o amor, neste poeta, está sempre intimamente ligado ao prazer físico. Os seus ensinamentos no tocante à traição e ao engano são disso um exemplo sugestivo. A infidelidade é um dos seus temas preferidos; a do homem, o que não surpreende, mas também (e especialmente) a da mulher. Os Amores são um verdadeiro manual da infidelidade conjugal, que é, ali, o tema de maior destaque, seja na descrição de episódios e cenas onde ela é o prato forte, seja no elencar de preceitos para a concretizar. E o terceiro livro da Arte de amar detém-se em ensinamentos cuidados com vista à sua prática em segurança.

Desculpa-se, é verdade, ou antes, justifica-se, com a afirmação de que os seus versos não têm por destinatárias mulheres casadas e respeitáveis matronas. Essa é, no entanto, uma cautela mal disfarçada, já que amiúde parece ser a essas mesmas, as casadas, que tais versos se destinam; ou, pelo menos, não são deles excluídas.

Industria a mulher na escolha dos amantes, o que pressupõe que se não resignem a ser mero objecto de sedução alheia: devem evitar os que se preocupam em demasia com a beleza e a elegância, peritos na arte de seduzir sem compromisso (Ars, 3.433-436). E ensina-as a iludir um marido, por matreiro e precavido que seja: como enviar mensagens de amor através de um escravo de confiança (escondidas debaixo da roupa, no aconchego do peito ou atadas às pernas ou, ainda, entre o pé e o calçado; escritas no próprio corpo, com leite fresco, que pó de carvão, mais tarde, deixará legíveis (Ars, 3.615-630); como furtar-se à vigilância de um marido severo, fingindo, por exemplo, dores de cabeça, ou invocando a necessidade de visitar uma amiga enferma, sua cúmplice, para, em casa dela, concretizar encontros furtivos, ou, ainda, frequentando banhos femininos, onde o amante previamente se terá introduzido, às escondidas. 
Se for surpreendida, acrescenta, não será grande o dano, desde que saiba usar de persuasão:

Mas, se vieres a ser apanhada em flagrante no meio de tua falta, e teus actos vergonhosos houverem de ser vistos por meus olhos, aquilo que eu bem tiver visto, afiança que o não vi assim tão bem; os meus olhos hão-de ceder às tuas palavras.

(Amores, 3.14.43-46)

E eis que, de súbito, todo o edifício cuidadosamente anunciado na abertura da Arte de amar é subvertido; o homem, de predador, converte-se em presa, e a mulher transforma-se, ela, em caçadora.

É o que sugere uma inesperada metáfora, quando recomenda às mulheres que saiam em busca do amor, como a loba procura as ovelhas, como a águia busca aves mais pequenas. E remata, de modo sugestivo:

$\mathrm{O}$ acaso tem a sua força em toda a parte; atira sempre o anzol; nas águas onde menos esperas, haverá peixe.

Muitas vezes, em vão vagueiam os cães por montanhas frondosas, e cai na armadilha, sem ninguém fazer nada, o veado.

(Ars, 3.427-430)

O jovem inexperiente, cuja sedução recomenda, é "uma presa novinha em folha, que veio cair na tua alcova" (Ars, 3.560), facilmente há-de ser vencido, "desde que só tu lhe ponhas a mão" (3.563). Mais tarde, consumada a conquista, dele diz que caiu no laço, "onde acabou, há pouco, de ser caçado" (3.591). E, quando pretende justificar-se por tantos ensinamentos ele, um homem, estar a dar ao inimigo, assim define a sua aparente incoerência:

Não revela o pássaro ao caçador como pode ser caçado, nem ensina o veado os cães assanhados a persegui-lo.

(Ars, 3.669-670)

O começo do livro III, o livro dedicado às mulheres, é bem explícito a respeito dos motivos que o levaram a compô-lo, motivos que pouco se coadunam com a mentalidade própria do seu tempo. Diriam os seus contemporâneos, de facto, que, à mulher, bastar-lhe-ia aprestar-se a ser seduzida, o 
mesmo é dizer, a desempenhar no amor um papel passivo. Não pensa assim o poeta; entende, pelo contrário, que devem ser dadas armas iguais a ambos os contendores. Se, nos dois primeiros livros, armou com um arsenal de instrumentos o "exército" dos homens (os "Dánaos", assim lhes chama), justo é, afiança, que forneça igual preparação às legiões das mulheres (as "amazonas"). Ao arrepio da mentalidade vigente, parece-lhe inaceitável que ambos os contendores partam para o duelo amoroso em condições desiguais e rejeita, portanto, que as mulheres sejam tratadas como "um povo sem armas entregue a homens armados" (Ars, 46). Nem a vitória seria digna, se isso acontecesse, acrescenta, irónico:

Parti para a batalha em igualdade de condições; que vença quem a mãe Dione favorecer, e o menino que voa sobre o mundo inteiro.

Não seria justo que enfrentásseis, despidas de armas, inimigos armados; se assim fosse, também para vós a vitória seria uma vergonha, ó varões.

(Ars, 3.3-6)

Em meio das múltiplas lições sobre as "manhas" de que deve a mulher fazer uso na prática do amor, justifica-se, sugestivamente; "olho por olho, dente por dente", eis um direito que dificilmente a sociedade do seu tempo seria capaz de reconhecer-lhe:

A meu ver, é permitido evitar a perfídia com perfídia;

e pegar em armas contra gente armada, as leis o consentem.

(Ars, 3.491-492)

Em matéria de direitos, entretanto, outras são as surpresas que um olhar atento a pequenos pormenores da poesia de amor ovidiana nos revela, nessa espécie de afã de subverter as regras do protocolo amoroso que os seus contemporâneos tacitamente seguiam. Por exemplo, o direito de aceitar e, implicitamente, o direito de recusar um amante. Suplica à sua amada, numa elegia dos Amores, que o aceite, nem que, para tanto, seja ela a impor as regras (2.27.23-24). E, no culminar do segundo dos livros dedicados aos homens, na Arte de amar, sublinhava, subtilmente, que Briseida, cativa de Aquiles em Tróia, era ela quem "consentia" que ele lhe tocasse (Ars, 2.713).

O passo mais significativo a este respeito figura numa curiosa elegia dos Amores, a todos os títulos surpreendente, inesperada e de rara originalidade. Trata-se da narrativa de um momento de amor não conseguido, a descrição 
de um insucesso na concretização física do desejo. Elegia de uma impotência momentânea, assim pode designar-se. Em meio do relato da frustração, tão realista quanto mórbido, afirma, inequívoco:

Havia em mim o desejo, sem dúvida, e aceitei-a; e de certeza fui por ela aceite; beijar, ser beijado, unir os corpos, tudo isso aconteceu.

(Amores, 3.7.47-48)

Repare-se na sucessão "aceitei e fui aceite", expressão aparente da equivalência hierárquica de ambos os parceiros. A verdade é que quem tem o poder de aceitar tem, igualmente, o poder de rejeitar; e esse poder, assim atribuído à mulher, em momento algum a sociedade romana com ele pactuava ou lhe reconhecia legitimidade.

Mais importante, ainda, será o direito ao prazer, ou seja, o direito à fruição do próprio corpo, na mesma medida em que ele era reconhecido ao parceiro masculino. É que esse era, por tradição, um direito inalienável do homem, que o não partilhava, por via de regra, com a sua companheira. Ela, como acima se disse, não passava de um instrumento ao serviço do prazer masculino, a quem servia com dupla função: proporcionar-lhe gozo físico e gerar-lhe descendência. Esse é o preconceito, essa a tradição que o terceiro livro da Arte de amar pretende contrariar; é o que se depreende da súmula dos seus versos iniciais, quando o poeta estimula as mulheres a prestarem atenção aos seus preceitos e a cumpri-los, porque "os direitos que lhes assistem o consentem" (Ars, 3.58); que direito é esse, enunciara-o poucos versos atrás: "amores que dão prazer" (Ars, 3.27).

É por isso que, em momento de rara beleza, incita as suas destinatárias a fruírem os seus encantos e o prazer que deles podem colher, enquanto a idade lho consente. São conselhos usuais, em muitos outros poetas, nesta época em que o carpe diem horaciano constituía doutrina comummente aceite e repetidamente apregoada; mas eram conselhos, as mais das vezes, dispensados a homens ou, pelo menos, não endereçados especificamente à mulher. É a ela, porém, que o poeta dirige estas palavras:

Enquanto vos for consentido e conservardes, ainda, a idade da Primavera, gozai; vão-se os anos, do mesmo modo que a água corrente;

nem a onda que passou voltará de novo a ser chamada, nem a hora que passou logra tornar atrás.

Há que aproveitar a idade. Com passo rápido se escapa a idade, e não é tão boa a que vem depois, quão boa foi a que veio antes. 
Estes gravetos que se vão tornando esbranquiçados, eu os vi da cor das violetas; desta braçada de espinhos foi-me ofertada uma aprazível coroa de flores.

Tempo há-de vir em que tu, que agora enjeitas os amantes, hás-de dormir, enregelada e velha, na solidão da noite...

(Ars, 3. 61-70)

Ovídio, porém, vai mais longe na subversão daquilo a que tem vindo a chamar-se nestas linhas "o protocolo amoroso" do seu tempo. A concretização física (sexual, portanto) do amor, a busca e obtenção de prazer que constitui, nas suas palavras, o objectivo último do amor, tudo isso é um processo que deve ser desenvolvido em conjunto pelos dois amantes. Este conceito de "parceria", se assim podemos chamar-lhe, representa, em si mesmo, uma novidade que suscitaria, por certo, a objecção dos seus concidadãos, não fora o caso de a subtileza com que é afirmada quase passar despercebida. Vejamos dois exemplos:

Roma era, em si mesma, uma cidade onde o sexo e o prazer eram uma realidade quotidiana. Vivia-se, no sugestivo dizer de Jean-Noël Robert, uma vida de "sexo em rede", onde mulheres e homens trocavam de parceiro, ao ritmo de um por noite. O professor francês vai mais longe, talvez, na crueza da sua afirmação de que a capital do Império vivia como que uma "feira de sexo" (Robert, 1997: 152-153). Ou seja, a prostituição era uma realidade do dia-a-dia. Ovídio contesta abertamente essa actividade comercial, assente na exploração do prazer, bem como o conceito que lhe está subjacente. É que, sustenta, no prazer, o resultado é igual para ambos os participantes; não é justo, por isso, que um deles pague e o outro seja pago:

Se é certo que Vénus há-de dar prazer igual aos dois, porque é que há-de ela vender, e ele há-de comprar?

(Amores, 1.10.33-34)

Por ser esse o seu conceito de amor, as duas partes da Arte de amar (os dois primeiros livros, por um lado, dedicados aos homens, e, por outro, o terceiro, destinado às mulheres) culminam na concretização física de quanto veio a ensinar-se, isto é na união sexual. Dirigindo-se aos homens, assume que, "para dar gozo, devem senti-lo igualmente a mulher e o homem" (Ars, 2.682); e, logo depois, acrescenta que tem ódio ao "acto de amor que não faz soltar ambos os parceiros” (2.683); eis porque tem 
ódio, também, àquela "que se entrega por ser preciso entregar-se” (2.685), o mesmo é dizer que só na partilha aceita o amor físico, não no dever de um dos parceiros:

Prazer cedido por dever não é prazer que me dê gozo; um dever, que nenhuma mulher o pratique comigo.

(Ars, 2.687-688)

E, quando está prestes a atingir-se o cume, recomenda prudência e sabedoria e que nenhum dos dois se atreva a tomar a dianteira, acabando, assim, por defraudar, no momento supremo, o outro. A regra, portanto, há-de ser o respeito por aquilo a que pode chamar-se a reciprocidade no prazer:

Mas não deixes para trás a tua parceira, desfraldando mais largas velas, nem seja mais rápido o ritmo dela que o teu;

avançai para a meta ao mesmo tempo; então, será pleno o prazer, quando, par a par, jazerem, vencidos, a mulher e o homem.

(Ars, 2.725-728)

Parece inquestionável, portanto, que o que se defende aqui é algo que não tem, ao que se saiba, correspondência nem em outros autores do tempo, nem na mentalidade dominante - o orgasmo simultâneo. Este não é assunto, pelo menos, que tenha preocupado a sociedade romana do século I a. C.

É certo, como em outro local escrevi já (André, 2006: 70-72), que destas palavras se não pode inferir inequivocamente uma defesa da dignificação do estatuto da mulher ou uma afirmação de respeito pelos seus direitos, no plano sexual, terreno onde ela era sistematicamente secundarizada, como se viu. Legítimo será interpretar que esta posição ovidiana colha a sua motivação no pressuposto de que essa será a prática que maior prazer proporciona ao parceiro masculino. O estudo atento da obra ovidiana de temática amorosa deixar-nos-á, sempre, na incerteza, tanto mais que a literatura não é compaginável com dogmas. Seja como for, é indubitável a atenção dada à mulher; e o primado que lhe é conferido no terceiro dos livros da Arte de amar em momento algum é de desprimor. Por contraditório que seja o autor, ele é o único, de entre os vários poetas de amor do seu tempo, que leva o homem a pensar no prazer da mulher, e não apenas no seu (Lilja, 1965: 199). Isso é já uma manifestação de originalidade, que não pode ter deixado de chocar os seus contemporâneos; ou seja, como afirma Jean-Noël 
Robert, algo há que muda na velha concepção do homem, enquanto senhor e dono da relação amorosa (Robert, 1997: 213). ${ }^{7}$

Pode, pois, acontecer - e importa insistir neste aspecto - que Ovídio esteja, tão-somente, a pensar no seu próprio interesse, o do parceiro masculino, tanto mais que tais conselhos, neste caso, são dados ao homem, em livro que o tem por destinatário, numa clara afirmação de que é a ele que compete gerir o ritmo, por assim dizer, do acto sexual, mesmo no plano físico; só a ele é reconhecido autodomínio para tanto, o que pressupõe que aquela simultaneidade e, por consequência, o inerente prazer que dela resulta para a mulher será, no fundo, uma concessão da parte dele que, assim, cede uma parcela do seu poder. ${ }^{8}$

Mas não deixa de ser um facto indesmentível que Ovídio sustenta, aqui, uma posição pouco usual. Confirma esta posição, de resto - e isso é particularmente significativo - no terceiro livro, aquele que toma por destinatárias as mulheres, a quem, como se disse, pretende municiar com armas iguais às dos homens. No culminar da doutrinação, tal como acontecera no livro anterior, pretende transmitir às suas destinatárias preceitos específicos sobre a melhor atitude a tomar no leito e sobre a arte de usar o corpo nesse ritual último do prazer; se usar de sabedoria, os dois, em simultâneo, hão-de experimentar os prazeres do amor:

Solte-se, do fundo das suas entranhas, a mulher e sinta os prazeres de Vénus, e a coisa há-de ser aprazível, ao mesmo tempo, aos dois.

Se, ao fechar o livro II, poderia ficar a sensação de que os conselhos prodigalizados aos homens permitiam supor que só ao parceiro masculino cabia a liderança na busca do prazer e que só ela possuía capacidade para dominar a situação e impor o ritmo, o final do livro III permite, sem ambiguidades, contrariar este ponto de vista e, uma vez mais, vislumbrar neste poeta latino de há mais de dois mil anos uma surpreendente afirmação da identidade da mulher na arte de amar, em pé de igualdade, digamos, com o seu parceiro masculino.

\footnotetext{
7 Vide, ainda, Laigneau (1999: 304-305).

8 As duas últimas décadas, em especial, foram férteis em abordagens da obra ovidiana sob esta perspectiva, nem todas, naturalmente, coincidentes, estudos esses a que a apreciação aqui feita é devedora: Lilja (1965: 192-216); Culham (1990); Cahoon (1990); Keuls (1990); Greene (1994 e 1998); a par de outros estudos de inegável interesse neste domínio.
} 
Aqui, de facto, como em tantos outros momentos, também a mulher podia (e devia, se lícito é interpretar a este ponto a alusão) exercer o comando nas guerreiras lides amorosas, para deitarmos mão de uma metáfora tão ao gosto ovidiano.

Já nos Amores, afinal de contas, o poeta lhe reconhecia essa capacidade de liderança, quando descrevia as artes e manhas com que a sua tão amada Corina o sujeitava e o "caçava"; assim o trazia "acorrentado", com palavras de meiguice, assim o deixava à porta, noite inteira, com a firmeza da sua recusa. Esses eram os meios de que devia a mulher deitar mão, para obter "longo reinado" (Amores, 2.19).

Só assim o prazer, objectivo último, como se disse, do amor ovidiano, poderia ser alcançado. E isso não era possível na sujeição, como aquela, por exemplo, a que estavam obrigadas as mulheres casadas:

Eis por que não conseguem as esposas ser amadas:

têm-nas consigo, sempre que assim querem, os maridos.

(Ars, 3.585-586)

Desta forma se compreendem melhor as Heroides, a que, no começo destas linhas, se fez referência. Aí, em dezoito das vinte e uma cartas, a expressão do amor, na primeira pessoa, cabe, por inteiro, à mulher, o que é, já em si mesmo, uma originalidade, de que se não conhecem precedentes na literatura latina.

São, na sua larga maioria, cartas de míticas amantes abandonadas, dirigidas àqueles que as abandonaram. E se, em muitas delas, se sucedem manifestações de súplica, por vezes a raiar a humilhação, na esperança de, dessa forma, obterem o retorno daquele que assim havia partido, essa não é a regra universal.

A carta de Medeia a Jasão, que por outra a trocara, recupera do mito e do tratamento que dele fez, por exemplo, Eurípides, o sentimento de profundo despeito, de orgulho ferido, e a lúcida premeditação da vingança. Não é de derrota a imagem que Medeia pretende dar de si, mas de triunfo; afinal, a própria traição de Jasão, foi ela quem lha proporcionou, ao dar-lhe os meios que lhe permitiram o sucesso na sua expedição. Com igual sabedoria saberá ela triunfar do golpe que ele lhe infligiu:

Estares vivo, teres uma noiva e um sogro poderosos, até isto de poderes ser um ingrato, tudo isso é obra minha.

Todos eles, verdade seja, já a seguir... Mas anunciar de antemão o castigo de que adianta? Imensas são as ameaças que a raiva pode parir. 
Para onde a raiva me levar, eu irei. Do que fizer, talvez venha a arrepender-me; também me arrependo de ter ajudado um homem infiel.

Que tenha em conta tudo isso o deus que me revolve, agora, o coração; é um não sei quê mais grandioso que a minha alma vai tramando.

(Her. 12.205-212)

Raiva e sede de vingança são igualmente a força que domina todo o discurso na carta de Dejanira a Hércules (Her. 9).

Eneias é olhado por Dido como um vulgar sedutor, sem força nem vontade, que se deixa condicionar por interesses de momento. O herói virgiliano, sobre cujo retrato, valha a verdade, o autor da Eneida derramara já vastas manchas de sombra, perde, aqui, muita da sua grandeza mítica, ante a enorme figura da Rainha de Cartago (Her. 7).

$\mathrm{Na}$ carta de Fedra a Hipólito (Her. 4), é ela quem toma a iniciativa, é ela quem assume a liderança no processo de sedução.

E, finalmente, a versão que transparece da carta de Helena a Páris (Her.17) e de uma outra, que este lhe dirige a ela (Her. 16), subverte algumas das notas mais comuns no mito: o príncipe troiano, assim parece legítimo inferir de ambas as cartas, não é o único responsável pelo rapto (se é que, na leitura ovidiana, esta palavra faz algum sentido); Helena, de facto, sugere-lhe subtilmente a iniciativa e alguns dos estratagemas para a concretizar, como se a fuga para Tróia fosse, afinal, um projecto assumido a dois, numa cumplicidade ausente da maior parte das versões do mito.

Muitos outros exemplos poderiam ser aduzidos, todos eles a demonstrar o protagonismo da mulher nestas cartas de sujeito feminino. Poderá dizer-se que, na maior parte dos casos, Ovídio não é propriamente original, já que tais interpretações colhem inspiração em conhecidas versões dos respectivos mitos. Não é isso, porém, o que está aqui em causa ou, pelo menos, não é apenas isso. O que merece ser destacado é o facto de Ovídio ter decidido juntar num só livro, numa estrutura coerente e em obediência, por certo, a um desígnio premeditado, um conjunto de episódios míticos onde as mulheres que neles intervêm assumem inequívoco protagonismo; e, o que é mais importante, o poeta deixa-as a narrar, na primeira pessoa, a sua versão dos factos. Essa, sem dúvida, é a sua grande originalidade, numa subtil estratégia, porventura eivada de ironia, que, por isso mesmo, pode ter passado despercebida aos seus contemporâneos.

${ }_{9}$ Não existe, ainda, desta obra tradução portuguesa. Como as demais, esta é de minha responsabilidade. 
Assim se compreende melhor toda a teorização, não menos irónica, como no início se afirmou, que pode estar subjacente aos Remédios de amor, ou melhor, "remédios para males de amor". Só uma concepção de que a mulher é quem, de facto, lidera o processo de sedução, ao arrepio de quanto dissera nos dois primeiros livros da Arte de amar e ao arrepio, também, da mentalidade vigente no seu tempo, pode justificar tão minuciosos preceitos sobre como resistir, não aos encantos femininos, pois não é disso que se trata, mas à liderança feminina.

Grande parte da obra ovidiana, dir-se-á, contradiz esta interpretação. Será verdade. Mas não o é menos que, em todos os passos citados, é legítimo vislumbrar uma persistente ironia, quem sabe se subtilmente apostada em minar e subverter os fundamentos do protocolo amoroso, de matriz inequivocamente masculina, da Roma de Augusto.

\section{Referências bibliográficas}

André, Carlos Ascenso (2006), Caminhos do amor em Roma: sexo, amor e paixão na poesia latina do séc. I a. C. Lisboa: Livros Cotovia.

Cahoon, Leslie (1990), "Let the Muse Sing on: Poetry, Criticism, Feminism, and the Case of Ovid”, Helios, 17(2), 197-211.

Culham, Phylis (1990), "Decentering the Text: the Case of Ovid", Helios, 17(2), 161-170.

Fantham, Elaine et al. (1994), Women in the Classical World: Image and Text. New York - Oxford : Oxford University Press.

Gourevitch, Danielle; Raepsaet-Charlier, Marie-Thérèse (2001), La femme dans la Rome antique. Paris, Hachette.

Green, C. M. C. (1996), "Terms of Venery: Ars amatoria I", Transactions of the American Philological Association, 126, 221-263.

Greene, Ellen (1994), "Sexual Politics in Ovid's Amores 3.4, 3.8 and 3.12", Classical Philology, 89(4), 344-350.

Greene, Ellen (1998), Erotics of Domination: Male Desire and the Mistress in Latin Love Poetry. Baltimore \& London: The Johns Hopkins University Press.

Grimal, Pierre (1995), L'amour à Rome. Paris: Éditions Payot et Rivages.

Keuls, Eva, (1990), "The Feminist View of the Past: A Comment on the 'Decentering' of the Poems of Ovid", Helios, 17(2), 221-224.

Laigneau, Sylvie (1999), La fermme et l'amour chez Catulle et les Élégiaques augustéens. Bruxelles: Latomus.

Lilja, Sara (1965), The Roman Elegists' Attitude to Women. Helsinki: Suomalainen Tiedeakatemia.

Robert, Jean-Noël (1997), Eros romain: sexe et morale dans l'ancienne Rome. Paris: Les Belles Lettres. 